\title{
The role of path choice and traffic assignment models in evacuation
}

\author{
M. L. De Maio \\ DIMET, Dipartimento di Informatica, Matematica, Elettronica e \\ Trasporti, Università degli Studi Mediterranea di Reggio Calabria, Italy
}

\begin{abstract}
In this paper a state of the art of path choice and traffic assignment models in road emergency conditions is reported. The approaches proposed in literature are classified, distinguishing two approaches for path choice and three approaches for traffic assignment (static, pseudo dynamic and dynamic). In literature, several applications of models in emergency conditions are available: at the beginning models specified in ordinary conditions were applied in emergency conditions. Afterwards, a first generation of models specified in emergency conditions was proposed. After 9/11 and Katrina Hurricane a second generation of emergency conditions models was specified. Evolution of models applied in emergency conditions is presented in this paper: first, models in ordinary conditions are treated; second, models in emergency conditions are treated. In the last ten years several applications of models in emergency conditions have been carried out. Main applications in emergency conditions are summarized in this paper.
\end{abstract}

Keywords: path choice, traffic assignment, static, dynamic, emergency conditions.

\section{Introduction}

Transportation systems analysis in emergency conditions implies the necessity to tackle a number of issues which differ from the same analysis in ordinary conditions [1]. Among these issues, path choice and traffic assignment on a road transportation network are relevant: these topics were previously treated in [2-4] and [5]. Some other relevant topics, which will not be treated in this paper, like travel demand models and travel demand simulation [6-10], evacuation planning process and planning tools [11-15], design of paths for emergency 
vehicles [16-20], were also treated by researchers in emergency conditions and a wide literature is available. The question is related to the capacity of models and methods, usually used in ordinary conditions, to properly simulate transport systems in emergency conditions. Network conditions and travel demand change when emergency occurs. Thus models and methods adopted have to represent, on one side, behaviour of users which evacuate and, on the other side, timevarying conditions of the network. Dynamic Traffic Assignment (DTA) models may be a possible way to be explored. Analysis of literature related to models applied in emergency conditions reveals an evolution, related to an increased attention on emergency occurrence and an increased computation power. Applications carried out in the last ten years in emergency conditions using DTA models are summarized in this paper.

After this introductive section, three sections follow. The first one is related to path choice and traffic assignment models in ordinary conditions. The second one is related to path choice models and traffic assignment models in emergency conditions. The third one reports some examples of applications on real networks. Final remarks are reported.

\section{Ordinary conditions}

Network flows and performances, during the reference time period, are obtained by means of mathematical models. Travel demand is defined by a sequence of choices dimensions related to departure time, destination, mode and path, dealt in this paper. Traffic assignment models simulate how travel demand and transport supply interact in transportation systems, allowing calculation of performances (costs) and vehicular flows on each supply element of the network (link). The path choice model is a component of traffic assignment model. It is worth noting that interactions occur not only inside the transport system, as in [21]. Moreover, a supply elements like fare system influence users, resulting in demand level variations in path and mode dimensions [22].

This section is composed by two sub-sections, the first related to path choice models in ordinary conditions and the second related to traffic assignment models in ordinary conditions.

\subsection{Path choice models in ordinary conditions}

In relation to path choice models in ordinary conditions, two main approaches are available in literature:

- models based on random utility theory (Random Utility Models - RUM), where random residuals take into account uncertainties;

- $\quad$ models based on fuzzy utility theory (Fuzzy Utility Models - FUM), where uncertainty is expressed through the possibility.

RUM are consolidated and many applications are available in literature. Various RUM specifications can be derived by assuming different joint probability distribution functions for the random residuals.FUM are not as 
commonly used as RUM models. Few applications are available in literature concerning the route choice dimension [23].

\subsection{Traffic assignment models in ordinary conditions}

Traffic assignment models may be classified according to three main approaches: static models, pseudo dynamic models and dynamic models.

STA models are based on the hypothesis of transport system in stationary conditions. Link performance variables may depend on flows or not: fixed costs result in non-equilibrium assignment models (uncongested networks) whereas variable costs lead to equilibrium traffic assignment models (congested network). User equilibrium is got when "the journey times in all routes actually used are equal and less than those which would be experienced by a single vehicle on any unused route" [24]. Another equilibrium approach is the system optimum, explained by the second Wardrop principle: "At equilibrium the average journey time is minimum".

A pseudo dynamic approach may be used to obtain correct information about the equilibrium state of the system analysed, when link flows are not steady and demand overcomes system capacity. The pseudo dynamic approach allows applying the static models on discrete time intervals, in which the hypotheses of STA models are not violated.

The hypothesis of stationary conditions typical of STA models is not acceptable whenever relevant changes in demand and supply system occur. Models able to simulate dynamics may be within-day models, which describe intra-periodal dynamics, or day-to-day models, inter-period dynamics. In this paper we are going to focus our attention on the within day dynamics models also referred in literature as Dynamic Traffic Assignment models (DTA).The equilibrium concept is formulated in a different way when not steady conditions are considered: two kinds of extensions are needed. First, users' knowledge of travel time is not perfect because travel time on links vary over time: then, the stationary hypothesis cannot be accepted. Hence, users choose the route characterized by the least travel time in relation to the actual experienced times on the network, which depend on the departure time. Second, for each o-d pair users experience the same travel time only if the departure time is the same.

\section{Emergency conditions}

Transport users have no experience of the network in emergency conditions and their choices are influenced by experience of the network in ordinary conditions: therefore, equilibrium, as stated in static conditions, cannot be achieved. Researchers have to develop traffic assignment models able to reproduce human behaviour when non-ordinary conditions occur. It is worth underlying that some DTA models specified in ordinary conditions were applied both in ordinary and emergency conditions. In the following sections DTA models both specified in ordinary conditions and in emergency conditions are referred to describe components of the DTA models. A traffic assignment model is composed by a 
demand model, a supply model and an interaction model. In relation to demand model, in this paper, we are interested in path choice model, which features are explained in paragraph 3.1. Supply model classification is described in paragraph 3.2.1; demand-supply interaction model is described in paragraph 3.2.2. The classification proposed is summarized in Figure 1.

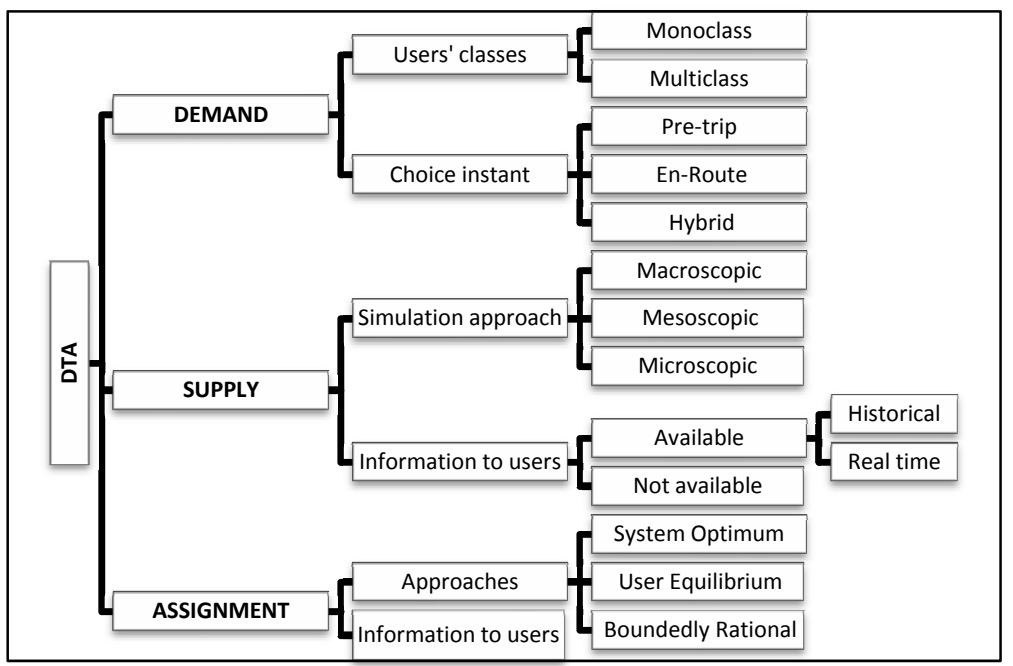

Figure 1: DTA in emergency conditions.

\subsection{Path choice demand models in emergency conditions}

In this section, some elements of classification for path choice models are presented. It is worth underlying that considered classification elements are related to path choice models applied but not necessarily specified in emergency conditions. Two classification criteria are considered. First of all, users may be divided into classes: each class is defined by a specific behavioural rule. Many researchers considered one behavioural rule (monoclass approach). Sometimes more than one behavioural rule is considered (multiclass approach) $[25,26]$. The second classification criterion is related to identification of the instant in which users choose [25, 27]: three approaches for dynamic traffic assignment in evacuation conditions are considered by Pel et al. [26]. The pre-trip approach assumes that users choose the route before departing, basing their choices on previous experiences. The en-route approach assumes that users choose at each node of the network and choices are influenced by some factors which may change. The hybrid approach assumes that user chooses a path before leaving and during the trip update the pre-trip choice, adapting it to his/her actual network condition. Figure 1 presents the explained classification. 


\subsection{Traffic assignment models in emergency conditions}

The assumptions of STA models do not allow reproducing changes in demand and supply which may occur in emergency conditions. Anyway, several applications of STA models in emergency conditions are available in literature.

In [28] the pseudo-dynamic approach is developed: evacuation time is obtained but flows conditions during the evacuation phenomenon are not available. After the Three Mile Island accident (USA, 1980s) a first generation of models able to simulate traffic assignment in emergency conditions was born: static models were applied to sub-intervals of the reference period.

Several researchers developed the dynamic approach in emergency conditions. In addition to the equilibrium definition proposed in paragraph 2.2, specifically in relation to emergency conditions, it is possible providing a different dynamic equilibrium definition. In general the equilibrium concept is based on exact users travel time perception and users' experience on the network. When the equilibrium is reached, all users experience the same travel time. In emergency conditions, which rarely occur, users have no experience of the network: equilibrium, as defined in ordinary conditions, cannot be achieved. In order to introduce equilibrium in emergency conditions it is necessary to define a perceived utility. Attributes may be travel time, departure time, network reliability, forecasted conditions, early/late penalty and so on. Therefore, the Wardrop equilibrium concept can be re-write in the following way: "the perceived utilities of all routes actually used are equal and less than those which would be experienced by a single vehicle on any unused route". In [29], the perceived utility is called payoff and dynamic equilibrium is stated as follows: "A dynamic equilibrium solution is the set of departure rates over a time interval $\mathrm{T}$ that a) provides all identical commuters the same payoff; and, b) has a utility greater than the utility obtained by departing at a time outside the interval T".

In relation to dynamic traffic assignment models available in literature, a second generation of models able to simulate traffic assignment in emergency conditionswas developed after $9 / 11$, thanks to improved computational computer power. Hurricanes, tsunamis, earthquakes and nuclear disasters happened over the last ten years make more urgent the treated issue. A lot of studies are carried out applying DTA in emergency conditions.

\subsubsection{Traffic assignment models in emergency conditions: supply}

Supply system can be simulated using three different approaches: macroscopic, mesoscopic and microscopic. Each approach is characterized by a different aggregation level and different mathematical relationships which model supply [30]. Used cost functions may be aggregate or disaggregate.

Macroscopic DTA models provide mathematical relationships among aggregate variables: density, flow, average speed. Similarity between traffic streams and fluid streams leads to the beginning idea for macroscopic models. Mahamassani [25] used macro models to describe vehicles interactions in the traffic stream. Goldblatt and Weinisch [31] used macroscopic models in order to describe link traffic flows. The macroscopic model is used also in [26]. 
In mesoscopic models, traffic flows is composed by homogeneous groups of vehicles called packs. The packs moving and interactions are simulated, using relationships typical of macroscopic models. This kind of models is not able to describe behaviour of each user but it may be more or less accurate depending on the packs size. A mesoscopic approach is used by Ben Akiva et al. [27].

Microscopic DTA models are characterized by disaggregate cost functions associated to links and nodes. Information (historical and/or real time) provided to users is a relevant supply feature. Therefore, both availability/unavailability and the kind of information provided are relevant (Figure 1).

\subsubsection{Traffic assignment modelsin emergency conditions: Assignment}

Peeta and Ziliaskopoulos [32] distinguished two classes of DTA models: analytical, based on mathematical formulations and explicit constraints (system optimum, if evacuation plan is available, or user equilibrium, otherwise) and simulation-based. In addition to this Mahmassani [25] proposed an analytical model called boundedly rational that consists of pre-fixed behavioural rules: users consider an alternative only if they will receive a gain over a threshold from choosing it.

Information achieved by users through ATIS influence users' choices: the compliance level has to be taken into account during the simulation process [33]. The kind of information available provokes a different influence on users' behaviour. For this reason information to users is a part of traffic assignment models. The main aim is to evaluate if it is worth supporting costs related to traveller information, comparing it with the benefits got by congestion reduction.

According to classification proposed in Figure 1, various dynamic assignment applications are available in literature. Taking account of the time in which users choose and analytical models approaches, Mahmassani [25] considered four assignment rules and, as a consequence, four users' classes. Ben Akiva et al. [27] considered four cases in relation to information available.

\section{Experimentations in emergency conditions}

Traffic assignment models were applied on emergency situations in various research works. Experimentations on test and real network in emergency conditions reveal several difficulties and critical points, related to hypothesis on users' behaviour and calibration procedure. In the following sections a review of experimentations specifically carried out in emergency conditions is reported.

\subsection{Calibration of traffic assignment models in evacuation conditions}

Models used in evacuation conditions can be calibrated by means of offline or online procedures. The former allows an estimation of parameters using historical observed data but parameters obtained are able to reproduce ordinary conditions. The online estimation procedure correct parameters estimated using the offline procedure, taking account of the current traffic on the network. 
One problem faced by researchers is related to congruence between link cost functions calibration and demand parameters calibration. In [34] a formulation to obtain parameters of link performance functions and demand values is proposed.

Unavailability of data over extended period in emergency conditions makes difficult models calibration. Two problems are identified in [30]: first, monitoring users' behaviour during an evacuation is difficult and setting up an evacuation experiment is too costly; second during an evacuation experiment people are aware that the emergency is not actually occurring.

\subsection{Applications of traffic assignment models in evacuation conditions}

In the followings some of the applications in evacuation conditions available in literature are summarized and classified in Table 1.

Table 1: Applications.

\begin{tabular}{|c|c|c|c|c|c|c|c|}
\hline $\begin{array}{l}\text { Assignment } \\
\text { approach }\end{array}$ & $\begin{array}{c}\text { Supply } \\
\text { Simulation } \\
\text { approach } \\
\end{array}$ & $\begin{array}{c}\text { Demand } \\
\text { Users' } \\
\text { classes } \\
\end{array}$ & $\begin{array}{c}\text { Demand } \\
\text { Choice } \\
\text { instant } \\
\end{array}$ & $\begin{array}{c}\text { Where } \\
\text { application is } \\
\text { done }\end{array}$ & $\begin{array}{l}\text { Information } \\
\text { to users }\end{array}$ & $\begin{array}{l}\text { Simulation } \\
\text { tool }\end{array}$ & Ref. \\
\hline $\mathrm{UE}$ & Mesoscopic & Multiclass & Hybrid & Toronto & Yes & $\begin{array}{l}\text { OSTE + } \\
\text { DynusT }\end{array}$ & {$[35][34]$} \\
\hline $\mathrm{UE} / \mathrm{SO}$ & Mesoscopic & Multiclass & En-route & Phoenix & Yes & DynusT & {$[36]$} \\
\hline $\mathrm{SO}$ & Mesoscopic & $\begin{array}{c}\text { Monoclas } \\
\mathrm{s}\end{array}$ & - & Evanston & Yes & $\begin{array}{c}\text { Specifically } \\
\text { created }\end{array}$ & {$[37]$} \\
\hline $\mathrm{UE} / \mathrm{SO}$ & Mesoscopic & Multiclass & - & Boston & Yes & Dynamit-E & [38] \\
\hline $\mathrm{UE} / \mathrm{SO}$ & Macroscopic & $\begin{array}{c}\text { Monoclas } \\
\text { s }\end{array}$ & - & $\begin{array}{c}\text { Indian Point } \\
\text { Energy Center }\end{array}$ & - & PCDYNEV & {$[31]$} \\
\hline $\mathrm{UE} / \mathrm{SO}$ & Macroscopic & Multiclass & Hybrid & Zeeland & Yes & EVAQ & {$[26]$} \\
\hline $\mathrm{UE}$ & Microscopic & - & Hybrid & - & - & OREMS & [39] \\
\hline - & Microscopic & & - & New Orleans & - & $\begin{array}{c}\text { TRANSISM } \\
\mathrm{S} \\
\end{array}$ & {$[40]$} \\
\hline $\mathrm{UE} / \mathrm{SO} / \mathrm{BR}$ & Macroscopic & Multiclass & $\begin{array}{l}\text { Pre-trip } \\
\text { En-route }\end{array}$ & Minneapolis & Yes & $\begin{array}{c}\text { Dynasmart- } \\
\text { P }\end{array}$ & [41] \\
\hline $\mathrm{UE} / \mathrm{SO} / \mathrm{BR}$ & Macroscopic & Multiclass & $\begin{array}{l}\text { Pre-trip } \\
\text { En-route }\end{array}$ & Texas & Yes & $\begin{array}{c}\text { Dynasmart- } \\
\text { P }\end{array}$ & {$[42]$} \\
\hline $\mathrm{UE}$ & Mesoscopic & - & - & Texas & - & $\begin{array}{c}\text { Cube } \\
\text { Avenue }\end{array}$ & {$[43]$} \\
\hline UE/SO & Microscopic & - & $\begin{array}{l}\text { Pre-trip } \\
\text { En-route }\end{array}$ & Virginia & . & VISSIM & [43] \\
\hline
\end{tabular}

UE = User Equilibrium, $S O=$ System Optimum, BR=Boundedly Rational

In [35], the application is referred to Toronto: a user optimal solution is obtained and route guidance is divulgated to private users. The model is able to simulate private users' behaviour and design transit vehicles routing. The main aim of these studies consists of obtaining an optimal spatio-temporal evacuation (OSTE) model and tool that helps evacuees in making their choices.

A system optimum analytical model is proposed in [36]. A mesoscopic approach is used to model transport supply. The application is carried out in Evanston. The model proposed is able to design optimal contraflow schemes for large scale network. The focus of this work is identifying network capacity not optimally used and calculating an optimal capacity reversibility scheme.

The system optimum approach and the user equilibrium approach have been integrated in [37] by splitting the evacuation procedure into two phases: during 
the first phase users reach some safe zones using the best route (system optimum approach); during the second phase, users move to the final destination choosing the path with a user equilibrium approach. Emergency is due to a bomb threat during an Arizona Cardinalis football game. The main aim is proposing an optimal zone-based vehicle evacuation strategy based on an optimizationsimulation framework.

In [38] application is related to the city of Boston and regards evacuation of the central business district. The contraflow strategy is considered and simulated. Optimal route guidance is communicated to a specific group of users. Some other users do not receive any route guidance. Simulation of highway performances and evaluation of measures for improving efficiency are the main purposes of this work.

An activity based approach is applied in [31]. The assignment is user equilibrium but it tends to minimize time spent by users on the network. The proposed application regards the Indian Point Energy Center.

The Zeeland network is chosen for the application in [26]. The transport supply model proposed is macroscopic and a hybrid approach is assumed to describe path choice. In relation to assignment, user equilibrium approach is used whether the evacuation is voluntary (no evacuation plan), and system optimum approach is adopted whether the evacuation plan is available. Travel demand is simulated using a multiclass approach. The proposed model can function both as a decision support system and an evacuation strategy designer.

The Oak Ridge National Laboratory (ORNL) developed a simulation and analysis model for evacuation (OREMS) which is currently used by the Department of Defense and the Federal Emergency Management Agency (FEMA) [39]. At the beginning it was developed in relation to army depots evacuation and to nuclear power-plants evacuation. The approach used for supply in OREMS is macroscopic. Assignment is user equilibrium. Users may choose route both pre-trip and en-route. It is possible to estimate evacuation times, develop alternative evacuation plans, and evaluate operational strategies.

Los Alamos National Laboratory (LANL), part of the Federal Highway Administration's (FHWA), developed TRANSIMS, a simulation model able to simulate disaggregated travel demand and to reproduce stochastic and dynamic nature of transportation systems. It was not born specifically to simulate emergency situations. In [40] TRANSIMS was applied in emergency situations.

In [41] and [42] the mesoscopic model for traffic simulation Dynasmart [25] was applied in evacuation conditions. A macroscopic approach is used for supply simulation whereas a multiclass approach is used for demand simulation. Assignment may be System optimum, User equilibrium or Boundedly-rational. Route choice can be pre-trip or en-route. In [41], Dynasmart-P, which is the planning version of Dynasmart, is applied in Minneapolis considering a hypothetical emergency situation, for that evacuation of the sell-out crowd in the Metrodome is necessary. The main aim of the application is evaluating the alternative evacuation strategies. In [42] Dyanasmart-P is applied in the area Houston-Galveston: people who live there have to be evacuated and contra-flow lanes actions effectiveness are evaluated. 
In the same area of Houston-Galveston other researchers [43] applied a supply mesoscopic model in order to support planners and decision makers during evacuation. Data acquired during Hurricane Rita are used. In [43], a microscopic supply model is used in order to evaluate a plan for traffic control.

\section{Final remarks}

The paper dealt with the path choice and traffic assignment models specified and/or applied in emergency conditions. Classifications of models available in literature are proposed. The way path choice and traffic assignment models evolved in the past is represented. Some of the main applications carried out by researchers in the last ten years are summarized. Further research will aim to focus on new models specified in emergency conditions and their application.

\section{References}

[1] Russo F. and Vitetta A., Risk evaluation in a transportation system. International Journal of Sustainable Development and Planning, 1 (2), pp. 170-191, 2006.

[2] Vitetta A., Musolino G. and Marcianò F.A., Safety of users in road evacuation: Supply and demand-supply interaction models for users. WIT Transactions on the Built Environment, Volume 96, Urban Transport XIII, Urban Transport and the Environment in the 21st century, Brebbia C. A. (ed.), WIT Press, Southampton, pp. 783-792, 2007.

[3] Vitetta A., Musolino G. and Marcianò F. A., Safety of users in road evacuation: calibration of cost functions and simulation. WIT Transactions on the Built Environment, Volume 101, Urban Transport XIV, Urban Transport and the Environment in the 21st century, Brebbia C. A. (ed.), WIT Press, Southampton, pp. 715-725, 2008.

[4] Vitetta A., Musolino G. and Marcianò F.A., Safety of users in road evacuation: Modelling and DSS for transport supply and supply-demand interaction. WIT Transactions on Ecology and the Environment, Volume 120, Sustainable Development and Planning IV, vol.1, Brebbia C. A. (ed.), WIT Press, Southampton, pp. 475-484, 2009.

[5] Marcianò F.A., Musolino G. and Vitetta A., Within day traffic assignment and signal setting in road evacuation: a procedure with explicit path enumeration. WIT Transactions on the Built Environment, Volume 117, Safety and Security engineering IV, Guarascio M., Reiners G. Brebbia C. A. \& Garzia F. (ed.), WIT Press, Southampton, pp. 403-414, 2011.

[6] Russo F. and Chilà G., Safety of users in road evacuation: demand models. WIT Transactions on the Built Environment, Volume 96, Urban Transport XIII, Urban Transport and the Environment in the 21st century, Brebbia C. A. (ed.), WIT Press, Southampton, pp. 773-782, 2007.

[7] Russo F. and Chilà G., Safety of users in road evacuation: RP vs. SP surveys in demand analysis. WIT Transactions on the Built Environment, Volume 101, Urban Transport XIV, Urban Transport and the Environment 
in the 21st century, Brebbia C. A. (ed.), WIT Press, Southampton, pp. 703713, 2008.

[8] Russo F. and Chilà G., Safety of users in road evacuation: Modelling and DSS for demand. WIT Transactions on Ecology and the Environment, Volume 120, Sustainable Development and Planning IV, vol.1, Brebbia C. A. (ed.), WIT Press, Southampton, pp. 465-474, 2009.

[9] Russo F. and Chilà G., Demand models in road evacuation: a synopsis of recent contributions. WIT Transactions on the Built Environment, Volume 116, Urban Transport XVII, Urban Transport and the Environment in 21st Century, Pratelli \& Brebbia C. A. (ed.), WIT Press, Southampton, pp. 601614, 2011.

[10] Russo F. and Chilà G., A statistical approach to analyse user behaviour in road evacuation. WIT Transactions on the Built Environment, Volume 117, Safety and Security engineering IV, Guarascio M., Reiners G. Brebbia C. A. \& Garzia F. (ed.), WIT Press, Southampton, pp. 377-390, 2011.

[11] Russo F. and Rindone C., Safety of users in road evacuation: planning internal processes and guidelines. WIT Transactions on the Built Environment, Volume 96, Urban Transport XIII, Urban Transport and the Environment in the 21 st century, Brebbia C. A. (ed.), WIT Press, Southampton, pp. 825-834, 2007.

[12] Russo F. and Rindone C., Safety of users in road evacuation: the logical framework approach in evacuation planning. WIT Transactions on the Built Environment, Volume 101, Urban Transport XIV, Urban Transport and the Environment in the 21 st century, Brebbia C. A. (ed.), WIT Press, Southampton, pp. 751-760, 2008.

[13] Russo F. and Rindone C., Safety of users in road evacuation: Modelling and DSS for LFA in the planning process. WIT Transactions on Ecology and the Environment, Volume 120, Sustainable Development and Planning IV, vol.1, Brebbia C. A. (ed.), WIT Press, Southampton, pp. 453-464, 2009.

[14] Russo, F. and Rindone C., Planning in road evacuation: classification of exogenous activities. WIT Transactions on the Built Environment, Volume 116, Urban Transport XVII, Urban Transport and the Environment in 21st Century, Pratelli \& Brebbia C. A. (ed.), WIT Press, Southampton, pp. 639651, 2011.

[15] Russo, F. and Rindone C., The planning process and logical framework approach in road evacuation: a coherent vision. WIT Transactions on the Built Environment, Volume 117, Safety and Security engineering IV, Guarascio M., Reiners G. Brebbia C. A. \& Garzia F. (ed.), WIT Press, Southampton, pp. 415-425, 2011.

[16] Vitetta A., Quattrone A. and Polimeni A., Safety of users in road evacuation: design of path choice models for emergency vehicles. WIT Transactions on the Built Environment, Volume 96, Urban Transport XIII, Urban Transport and the Environment in the 21st century, Brebbia C. A. (ed.), WIT Press, Southampton, pp. 803-812, 2007.

[17] Vitetta A., Quattrone A. and Polimeni A., Safety of users in road evacuation: algorithms for path design of emergency vehicles. WIT 
Transactions on the Built Environment, Volume 101, Urban Transport XIV, Urban Transport and the Environment in the 21st century, Brebbia C. A. (ed.), WIT Press, Southampton, pp. 727-737, 2008.

[18] Vitetta A., Quattrone A. and Polimeni A., Safety of users in road evacuation: Modelling and DSS for paths design of emergency vehicles. WIT Transactions on Ecology and the Environment, Volume 120, Sustainable Development and Planning IV, vol.1, Brebbia C. A. (ed.), WIT Press, Southampton, pp. 485-495, 2009.

[19] Polimeni A. and Vitetta A., Dynamic vehicle routing in road evacuation: a model for route design. WIT Transactions on the Built Environment, Volume 116, Urban Transport XVII, Urban Transport and the Environment in 21st Century, Pratelli \& Brebbia C. A. (ed.), WIT Press, Southampton, pp. 627-638, 2011.

[20] Polimeni A. and Vitetta A., Dynamic vehicle routing in road evacuation: route design experimentation. WIT Transactions on the Built Environment, Volume 117, Safety and Security engineering IV, Guarascio M., Reiners G. Brebbia C. A. \& Garzia F. (ed.), WIT Press, Southampton, pp. 391-402, 2011.

[21] Gattuso D. and Musolino G., A simulation approach of fare integration in regional transit services. In: Algorithmic Methods for Railway Optimization. F. Geraets, L. Kroon, A. Schoebel, D. Wagner, C. Zaroliagis (eds.). LNCS volume n. 4359. Springer, pp. 200-218, 2007.

[22] Russo F. and Musolino G., Urban land-use transport interaction modelling: state of the art and applications. In Urban Transport XIII: urban transport and the environment in the 21st century. C. A. Brebbia (ed.), WIT Press, pp. 525-534, 2007.

[23] Quattrone A. and Vitetta A., Random and fuzzy utility models for road route choice. Transportation Research Part E, Volume 47, Issue 6, November 2011, Pages 1126-1139, 2011.

[24] Wardrop J.G., Some theoretical aspects of road traffic research. Proceedings, Institution of Civil Engineers, Part II 1, pp. 325-378, 1952.

[25] Mahamassani H, Dynamic network traffic assignment and simulation methodology for advanced system management applications. Networks and Spatial Economics, Volume 1, Numbers 3-4, 267-292, 2001.

[26] Pel A. J., Bliemer M.C.J. and Hoogendoorn S.P., EVAQ: A new analytical model for voluntary and mandatory evacuation strategies on time-varying networks, Proceedings of the 11th International IEEE Conference on Intelligent Transportation Systems, 2008.

[27] Ben Akiva M., Bierlaire M., Koutsopoulos H. and Mishalani R., Real time simulation of traffic demand-supply interactions within dynamit, In Transportation and network analysis: current trends. Miscellanea in honour of Michael Florian, pp. 19-36, Kluwer, 2000.

[28] Velonà P. and Vitetta A., Analisi e gestione di una rete di trasporto in condizioni di emergenza mediante procedure d'assegnazione pseudo dinamica. In Evacuazione di sistemi urbani: Metodi quantitative per 
l'analisi dei sistemi di trasporto in condizioni di emergenza a cura di F. Russo, Franco Angeli Milano, 2004.

[29] Ramadurai, G., Ukkusuri, S. V., Zhao, J, and Pang, J. S., Linear Complementary Formulation for the Multi-user Class Single Bottleneck Problem. Transportation Research Part B: Methodological. Vol. 44(2), pp. 193-214, 2010.

[30] Musolino G. and Vitetta A., Short-term forecasting in road evacuation: calibration of a travel time function. In: Brebbia C. A. Pratelli, A. Eds, Urban Transport and the Environment in the 21st century, WIT Press, Southampton (GBR), pp. 615-626, 2011.

[31] Goldblatt R. and Weinisch K, Evacuation planning, human factors, and traffic engineering. TR news 238 May- June, 2005.

[32] Peeta S. and Ziliaskopoulos A.K., Foundations of Dynamic Traffic Assignment: the past, the present and the future, Networks and spatial economics, 2001.

[33] Pel A. J., Hoogendoorn S.P. and Bliemer M.C.J., Evacuation modelling including traveller information and compliance behaviour, Procedia Engineering, Elsevier press, 2010.

[34] Russo F. and Vitetta A., Reverse assignment: calibrating link cost functions and updating demand from traffic counts and time measurements. Inverse Problems in Science \& Engineering, 2011.

[35] Abdelgawad H. and Abdulhai B., Managing Large-Scale Multimodal Emergency Evacuations. Journal of transportation Safety and Security, 2010.

[36] Tuydes H. and Ziliaskopoulos A., Tabu-Based Heuristic for Optimization of Network Evacuation Contraflow. In The 85th Annual Meeting of the Transportation Research Board, 2006.

[37] Zheng H., Chiu Y. C., Mirchandani P. and Hickman M., Modelling of Evacuation and Background Traffic for an Optimal Zone-Based Vehicle Evacuation Strategy. In The 89th Annual Meeting of Transportation Research Board, 2010.

[38] Balakrishna R., Wen Y., M. Ben Akiva and Antoniou C., Simulation-Based framework for transportation management for emergencies. In The 87th Annual Meeting of the Transportation Research Board, 2006.

[39] Oak Ridge Evacuation Modelling System (OREMS). Oak Ridge National Laboratory, 2005.

[40] Naghawi H. and Wolshon B., Transit-based emergency evacuation modelling. Journal of transportation safety and security, 2010.

[41] Kwon E. and Pitt S., Evaluation of Emergency Evacuation Strategies for Downtown Event Traffic Using a Dynamic Network Model. Transportation Research Record, 2006.1922/2005: p. 149-155, 2006.

[42] Chiu Y.C., Texas Disaster Preparedness Study: Task 3 "Develop and Test Innovative Contraflow Applications/Operations". 2007.

[43] A.A.V.V., Proceedings from the Contra Flow Workshop. In Contra Flow Workshop. 2006. Orlando, FL, 2006. 